\title{
NOSTHE
}

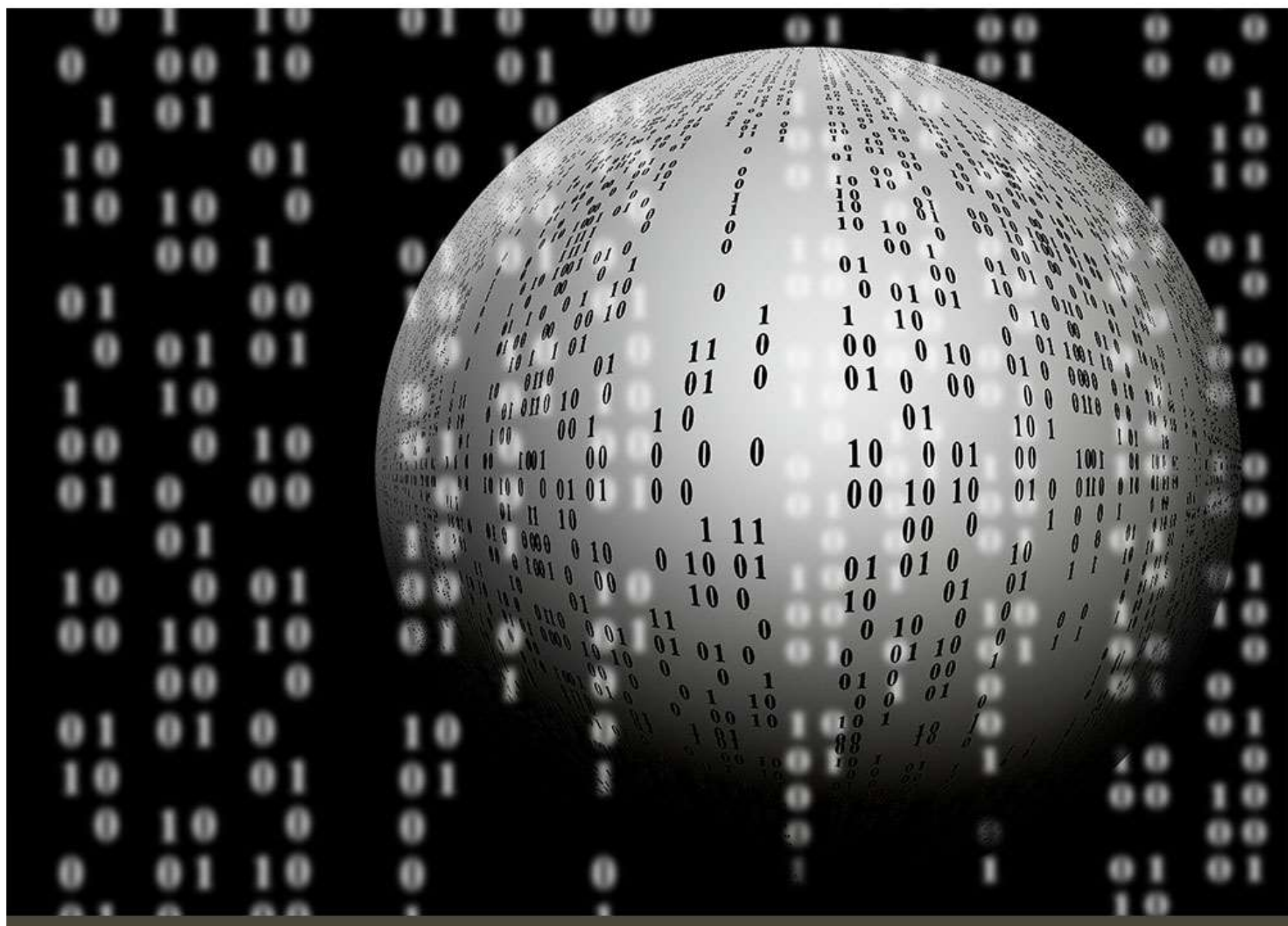

Volume 6, Issue 2, February 2019 www.ijosthe.com 


\section{Demand Forecasting of Spare Parts of Automobiles using Gaussian Support Vector Machine}

\author{
R. Mayur \\ Department of M.E \\ Roorkee, India \\ rmayurkrishnan@gmail.com
}

\author{
Baibhav Kumar \\ Department of ME \\ Roorkee, India \\ baibhav_kumar@yahoo.com
}

\begin{abstract}
Reordering motor vehicle spare parts for the purposes of stock replenishment is an important function of the parts manager in the typical motor dealership. Meaningful reordering requires a reliable forecast of the future demand for items. Production planning and control in remanufacturing are more complex than those in traditional manufacturing. Developing a reliable forecasting process is the first step for optimization of the overall planning process. In remanufacturing, forecasting the timing of demands is one of the critical issues. The current article presents the result of examining the effectiveness of demand forecasting by time series analysis in auto parts remanufacturing. A variety of alternative forecasting techniques were evaluated for this purpose with the aim of selecting one optimal technique to be implemented in an automatic reordering module of a real time computerized inventory management system.
\end{abstract}

Keywords - Warehouse, Sale Forecasting, Supply Chain Management, Support Vector Machine, ANFIS.

\section{I.INTRODUCTION}

In most manufacturing industries, including the automotive industry, after-sales services are a significant source of revenue, profit and competitive advantage [1]. According to [2] longlasting relationships are supported by customer satisfaction, which is increased by having effective value adding services in the vehicle aftermarket. In [2] further mean that the foundation of these value-adding services is the distribution of spare parts. Distribution of spare parts involves inventory holding which affects inventory carrying cost, total order cost as well as shortage cost. Equipment which the parts are used for can quickly change, production-, design- and demand-wise, which creates a high risk of obsolescence for spare parts. Moreover, it is challenging to achieve a balance between reducing obsolescence, inventory holding and shortage costs while offering competitive service to customers. The supply chain network and planning of spare parts is therefore important to an automotive company since it affects revenue, customer satisfaction and costs.

\section{II.RELATED WORK}

There are useful perspectives for the enterprises which use spareparts to give internal maintenance to their equipment. Barabadi et al. [1] base their predictions on the statistics models of products' reliability, influenced by factors such as the means of management, maintenance policies, driver's skills, etc., while Lengu et al. [2] propose to discard the supposition of normality in the time series and model the demand of the parts as Bernoulli processes, particularly in the Poisson distributions, taking advantage of the imminent nature of the spare-parts demand. Moon et al. [3] decided to develop a selection model among the forecast methods, in order to predict the performance of each method when forecasting the demand for naval parts in South Korea. Previously developed methods were used, and by means of a logistic regression, it was determined whether one or another method was better for forecasting purposes for the next period. Petropoulos et al. [4], performed a study about the forms of selecting time series forecasting methods, where they suggest that the forecast accuracy is influenced as explained below: i) For fast-changing data, cyclicality and randomness have the greatest (negative) effect, and the greater the forecast horizons, the greater the decrease in accuracy For intermittent data, the inter-demand interval has a greater (negative) effect than the coefficient of variation; iii) For every type of data, increasing the length of the series entails small positive effects. In addition, Sipper and Bulfin [5] propose a methodology to select the demand forecasting methods applied to planning and production management. Even though efficient and complex forecasting methodologies have been developed, there is little evidence of their implementation within the industry [6], and simpler methods, such as the simple moving average or simple exponential smoothing are often used instead [7]. It is also important to identify the nature of the item under study. This can be achieved when classifying them under different criteria, according to our needs and several studies on this matter have been performed, with classifications based on the periodicity of the demand [8], the manufacturing volume [9], or even more complex classifications [10] that should be of help for selecting proper methods and tools for modeling spare-parts behaviour [11].

\section{III.METHODOLOGY}

\section{Adaptive Neuro Fuzzy Inference system (ANFIS)}

\section{Step 1: Fuzzy C-Means (FCM) clustering}

It is used to generate a cluster collection, each cluster containing the data identified by a collection of similar identifiers. One of the processes of dividing data elements into classes is the grouping of data. In data clustering, the elements of the same class are as similar as possible and the elements of different classes are as different as possible. Depending on the type of 
data and the purpose for which clustering is used, different similarity measures can be used to position elements in classes, with the degree of similarity that controls how the clusters are formed.

Formally, let $\mathrm{V}(\mathrm{n} * \mathrm{k})$ be the wind data file $\mathrm{n} * \mathrm{k}$ by size array containing the wind data file vectors vi such that $\mathrm{V}=[\mathrm{v} 1$; v2; $\mathrm{v} 3 ;::: ; \mathrm{vn}]$, where each file carrier contains k number of entities. Let $\mathrm{c}$ be the number of groups and the total number of wind files, $2<=\mathrm{c}<\mathrm{n}$. The matrix $\mathrm{V}$ is inserted into the FCM algorithm, which is a list of cluster centers $\mathrm{X}=\mathrm{x} 1 ;$;::; $\mathrm{xc}$ is a membership matrix $U$, in which each element contains the total membership of a wind data file vk belonging to the group ci. FCM updates cluster centers and membership levels of each wind data file using the goal function.

\section{Step 2: ANFIS Classification}

The fuzzy grouping uses inference models based on adaptive neuro-fuzzy systems. ANFIS is a type of artificial neural network based on the Takagi Sugeno fuzzy inference system. Because it integrates both neural networks and the principles of fuzzy logic, it has the potential to capture the benefits of both in a single framework.

The adaptive inference system of neurofuzzle (ANFIS) [26] is a class of adaptive networks whose functionality corresponds to a fuzzy inference system (FIS) that automatically generates a fuzzy rule and membership functions (MF). The output of this system can be defined by the following equation:

$$
\begin{array}{r}
r=\sum_{k=1}^{n}\left\{\left(\left(\prod_{l=1}^{L} M F(k, l)(X(l))\left(Z^{k}\right)\right)\right.\right. \\
/\left(\sum_{k=1}^{n}\left(\prod_{l=1}^{L} M F(k, l)(X(l))\right)\right\}
\end{array}
$$

Where, MF is the membership function, $\mathrm{X}(l)(1=1,2, \ldots, \mathrm{L})$ is the $l$ th input and $Z^{k}$ is the output of $l$ th fuzzy rule. ANFIS adjusts the parameters of Sugeno type inference system using the neural networks. ypically, the network topology of the adaptive neurofuzzy inference system consists of connected nodes determined by parameters that change according to particular learning rules that minimize the error.

One possible set of rules is shown as an example in Equations : Rule 1: If $\mathrm{x}$ is equal to $\mathrm{a}_{1}, \mathrm{y}$ is equal to $\mathrm{b}_{1}$, and $\mathrm{z}$ is equal to $\mathrm{c}_{1}$,

$$
\text { then } f_{1}=p_{1} x+q_{1} y+r_{1} y+s_{1}
$$

Rule 2: If $\mathrm{x}$ is equal to $\mathrm{A}_{2}, \mathrm{y}$ is equal to $\mathrm{B}_{2}$, and $\mathrm{z}$ is equal to $c_{2}$,

$$
\text { then } \mathrm{f}_{2}=\mathrm{p}_{2} \mathrm{X}+\mathrm{q}_{2} \mathrm{y}+\mathrm{r}_{2} \mathrm{z}+\mathrm{s}_{2}
$$

\section{Gaussian Kernel based Support Vector Machine (SVM)}

This is for classification and regression problems. SVM classifies data into different classes by identifying a hyperplan (line) that separates learning data into classes. The hyperplane's identification, which maximizes the distance between classes, increases the probability of generalizing secret data. SVM offers the best classification performance i.e. the accuracy of the training set. It does not overflow the data.

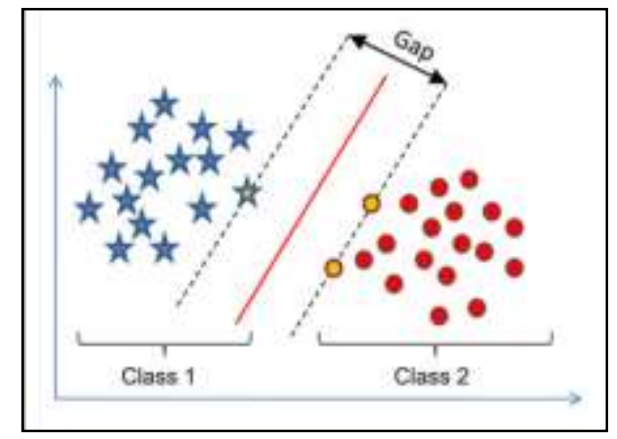

Figure 1: SVM Classifier

SVM does not make strong assumptions about the data. Show more efficiency in the correct classification of future data. SVM is classified into two categories, i. H. Linear and non-linear. In a linear approach, training data is represented by a line, i.e. hyperplane, shown separately.

Consider the problem of separating the set of training vectors belonging to two distinct classes,

$\mathrm{G}=\left\{\left(\mathrm{x}_{\mathrm{i}} ; \mathrm{y}_{\mathrm{i}}\right) ; \mathrm{i}=1 ; 2 ; ;: ; \mathrm{N}\right\}$ with a

hyperplane $\mathrm{w}^{\mathrm{T} *}(\mathrm{x})+\mathrm{b}=0$ (xi is the ith input vector, yi $\in$ $\{-1 ; 1\}$ is known binary target), the original SVM classi1er satisfies the following conditions:

$$
\begin{aligned}
& \mathrm{w}^{\mathrm{T}}{ }_{*_{\phi}}\left(\mathrm{x}_{\mathrm{i}}\right)+\mathrm{b} \geq 1 \text { if } \mathrm{y}_{\mathrm{i}}=1 \\
& \mathrm{w}^{\mathrm{T}}{ }^{*}\left(\mathrm{x}_{\mathrm{i}}\right)+\mathrm{b} \leq 1 \text { if } \mathrm{y}_{\mathrm{i}}=-1
\end{aligned}
$$

where $\phi: \mathrm{R}^{\mathrm{n}} \rightarrow \mathrm{R}^{\mathrm{m}}$ is the feature map mapping the input space to a usually high dimensional feature space where the data points become linearly separable.

The distance of a point xi from the hyperplane is

$$
d\left(x_{i}, w, b\right)=\frac{\left|w^{T} * \emptyset\left(x_{i}\right)+b\right|}{\left|w^{2}\right|}
$$

The margin is $2 /|w|$ according to its definition. Hence, we can find the hyperplane that optimally separates the data by solving the optimization problem:

$$
\min \emptyset(w)=\frac{1}{2}|w|^{2}
$$

For the inseparable linear problem, we first assign the data to another large space $H$ using a non-linear mapping, which we call $\Phi$. So we use the linear model to achieve classification in new space $H$. Through defined "kernel function" $k$, is converted as follows:

$$
\begin{gathered}
\max \sum_{i=1}^{l} a_{i}-\frac{1}{2} \sum_{i, j=1}^{l} a_{i} a_{j} y_{i} y_{j} k\left(\overrightarrow{x_{l}} * \overrightarrow{x_{J}}\right) \\
\text { s.t. } \sum_{i=1}^{l} a_{i} y_{i}=0 \quad 0 \leq \mathrm{a}_{\mathrm{i}} \leq \mathrm{C}, \\
\mathrm{i}=1,2, \ldots \ldots \ldots . .1
\end{gathered}
$$

And corresponding classification decision function is converted as follows:

$$
f(x)=\operatorname{sign}\left[\sum_{i=1}^{l} a_{i} y_{i} k\left(\overrightarrow{x_{\imath}} * \vec{x}\right)+b\right]
$$


The selection of kernel function aims to take the place of inner product of basic function. The kernel function investigates the non-separable problems as follows:

$$
k\left(x_{i} x_{j}\right)=\exp \left(-\gamma\left\|x_{i}-x_{j}\right\|\right.
$$

Based on the literature review up to this point, it was possible to decide that the best tool for modelling the automobile spare-parts demand, given its behaviour and little availability of information, is by means of a time series perspective, so that it has been decided to develop the ANFIS and GSVM models using only the information available in order to obtain forecasts. We can observe a sketched description of the selection process in Figure 2.

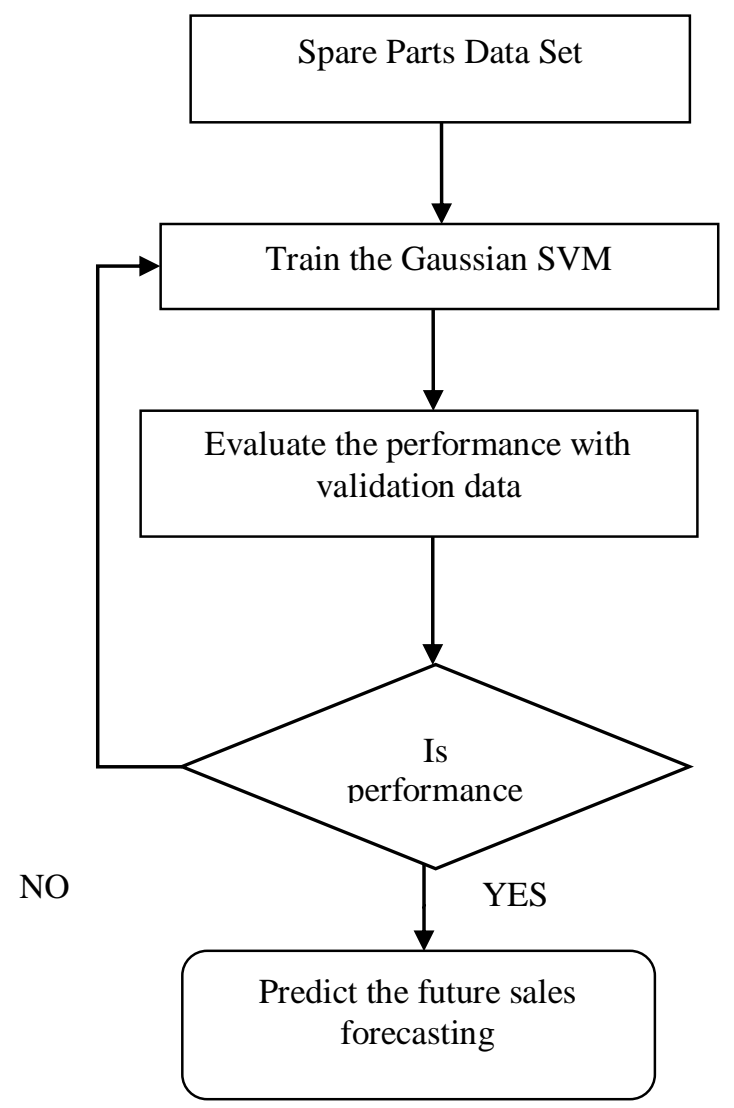

Figure 2: Flow Chart of Work

\section{IV.RESULT ANALYSIS}

\section{A. Dataset Description}

In this paper, 4 companies are studied from market analysis which contains details of 20 spare parts for 4 companies i.e. Toyota, Nissan, Renault and Ford. The data contains information about month, company, spare parts, monthly ordered spare parts, scrap and unused spare parts. The data collected from 2017-2018 from different spare part distributors. Description of dataset are given below:

Table I: Company List

\begin{tabular}{|l|l|}
\hline 1 & Toyota \\
\hline 2 & Nissan \\
\hline
\end{tabular}

\begin{tabular}{|l|l|}
\hline 3 & Renault \\
\hline 4 & Ford \\
\hline
\end{tabular}

Table II: Spare Part List

\begin{tabular}{|c|l|}
\hline 1 & AC Servicing \\
\hline 2 & Air Filter \\
\hline 3 & Battery - Diesel \\
\hline 4 & Battery - Petrol \\
\hline 5 & Brake Disc \\
\hline 6 & Brake Hose \\
\hline 7 & Clutch Replacement \\
\hline 8 & Front Brake Pads \\
\hline 9 & Front Bumper \\
\hline 10 & Front Fog Light \\
\hline 11 & Front Shock Absorber \\
\hline 12 & Front Windshield \\
\hline 13 & Fuel Filter - Diesel \\
\hline 14 & Fuel Filter - Petrol \\
\hline 15 & Headlight Assembly \\
\hline 16 & Rear Brake Shoe \\
\hline 17 & Rear Shock Absorber \\
\hline 18 & Spark Plug \\
\hline 19 & Tail Light Assembly \\
\hline 20 & Wiper Blades \\
\hline
\end{tabular}

\section{B. Performance Parameters}

\section{Mean Square Error (MSE)}

MSE of any estimator (classifier) measures the average squares of errors or deviations, i,e. the difference between the estimator and what is estimated. MSE is a risk function corresponding to the expected value of the squared error loss.

$$
M S E=\frac{1}{N}\left(\text { Target }_{\text {value }}-\text { Obtained }_{\text {value }}\right)
$$

\section{Root Mean Square Error (RMSE)}

RMSE is a parameter that determines the difference in squares between the output and the input.

$$
R M S E=\sqrt{M S E}
$$

In this research work the spare part dataset is used to predict spare part requirement for future using ANFIS classifier and gaussian kernel-based classifier. Table I illustrates performance analysis of both the classifiers.

Table I: Training and Testing Data Performance for

\begin{tabular}{|c|c|c|c|}
\hline \multicolumn{4}{|c|}{ Toyota } \\
\hline \multirow{3}{*}{$\begin{array}{c}\text { Testing } \\
\text { Data }\end{array}$} & ANFIS & 4.7408 & 2.1773 \\
\cline { 2 - 4 } & SVM & 0.0034 & 0.0584 \\
\hline
\end{tabular}




\begin{tabular}{|c|c|c|c|}
\hline \multicolumn{4}{|c|}{ Nissan } \\
\hline \multirow{3}{*}{$\begin{array}{c}\text { Testing } \\
\text { Data }\end{array}$} & & MSE & RMSE \\
\hline & ANFIS & 5.6941 & 2.3862 \\
\hline & SVM & 0.0019 & 0.0433 \\
\hline \multicolumn{4}{|c|}{ Ford } \\
\hline \multirow{3}{*}{$\begin{array}{c}\text { Testing } \\
\text { Data }\end{array}$} & & MSE & RMSE \\
\hline & ANFIS & 4.7408 & 2.1773 \\
\hline & SVM & 0.0034 & 0.0584 \\
\hline \multicolumn{4}{|c|}{ Renault } \\
\hline \multirow{3}{*}{$\begin{array}{c}\text { Testing } \\
\text { Data }\end{array}$} & & MSE & RMSE \\
\hline & ANFIS & 4.7408 & 2.1773 \\
\hline & SVM & 0.0034 & 0.0584 \\
\hline
\end{tabular}

\section{V.CONCLUSION}

This research provides an overview of various tools with different techniques used to predict the inventory control of taking into account different time scales. Several forecasting models that have their characteristics have been discussed. Furthermore, the accuracy of the predictive models and the source of the error were highlighted. It is difficult to evaluate the performance of different models because the existing applications were different. In this research work two classifier's performance are evaluated on the real-time dataset. MSE, RMSE are used as a performance parameter. From the result analysis it has been concluded that gaussian SVM outperforms better as compared to the ANFIS model.

\section{REFERENCES}

[1] Barabadi A, Barabady J, Markeset T. Application of reliability models with covariates in spare part prediction and optimization - A case study. Reliability Engineering and System Safety. 2014;123:1-7.

[2] Lengu D, Syntetos AA, Babai MZ. Spare parts management: Linking distributional assumptions to demand classification. European Journal of Operational Research. 2014;235:624-35.

[3] Moon S, Simpson A, Hicks C. The development of a classification model for predicting the performance of forecasting methods for naval spare parts demand. International Journal of Production Economics. 2013;143:449-54.

[4] Petropoulos F, Makridakis S, Assimakopoulos V, Nikolopoulos K. 'Horses for Courses' in demand forecasting. European Journal of Operational Research. 2014;237:152-63.

[5] Sipper D, Bulfin RL. Planeación y Control de la Producción. México: Mc. Graw Hill; 1998. [26] Huiskonen J. Maintenance spare parts logistics: Special characteristics and strategic choices. International Journal of Production Economics. 2001;71:125- 33.

[6] Syntetos AA, Babai Z, Boylan JE, Kolassa S, Nikolopoulos K. Supply chain forecasting: Theory, practice, their gap and the future. European Journal of Operational Research. 2016;252:1-26.

[7] Rego JRd, Mesquita MAd. Demand forecasting and inventory control: A simulation study on automotive spare parts. International Journal of Production Economics. 2015:1-16.

[8] Mohamed NMZN, Khan MK. Decomposition of manufacturing processes: a review. International Journal of Automotive and Mechanical Engineering. 2012:545-60.

[9] Bacchetti A, Plebani F, Saccani N, Syntetos AA. Empirically-driven hierarchical classification of stock keeping units. International Journal of Production Economics. 2013:263-74.
[10] Hemeimat R, Al-Qatawneh L, Arafeh M, Masoud S. Forecasting spare parts demand using statistical analysis. American Journal of Operations Research. 2016:113-20. 